\title{
Additional Approaches to Assess the Vietnam Provincial Competitiveness Index (PCI)
}

\author{
Diep Thanh Tung ${ }^{1,2}$ \\ ${ }^{1}$ Faculty of Economics, Laws and Foreign Languages, Tra Vinh University, Vietnam \\ ${ }^{2}$ Institute of Project and Regional Planning, Justus-Liebig-University, Germany \\ Correspondence: Diep Thanh Tung, Institute of Project and Regional Planning, Justus-Liebig-University, \\ Senckenbergstrasse 3, D-35390 Giessen, Germany. E-mail: Thanh.T.Diep@agrar.uni-giessen.de
}

Received: January 2, 2014

Accepted: January 14, 2014

Online Published: February 24, 2014

doi:10.5539/ibr.v7n3p1

URL: http://dx.doi.org/10.5539/ibr.v7n3p1

\begin{abstract}
To supply an additional approach to the current PCI rank, this study promotes a new rank based on technical efficiency scores. Components of PCI are used as inputs to produce outputs which are business indicators. While technical efficiency and PCI ranks are supplements for each other in annual assessments, the Malmquist index and its compositions may be long-term indicators to reflect the performance improvement of the local governments to attract investments.
\end{abstract}

Keywords: Vietnam Provincial Competitiveness Index, data envelopment analysis, Malmquist, bootstrap

\section{Introduction}

Since 2005 the U.S. Agency for International Development-supported Vietnam Competitiveness Initiative (USAID/VNCI) and the Vietnam Chamber of Commerce and Industry (VCCI) have developed the annual index, namely the Provincial Competitiveness Index (PCI). The purpose of the PCI is to measure and assess the standards of economic governance in Vietnam's 63 provinces from the perspective of private sector businesses. As expected, PCI has become the important voice of enterprises while policy-makers in provinces and municipalities have shown more interests on PCI in order to identify where and how they can pursue economic governance reforms to attract investment. According to the official website of PCI, until 2013, there are over 40 provinces conducting PCI diagnostic workshops to engage public-private dialogue and many activities of provinces done to improve competitive capacity of the provinces (PCI, 2013).

To reflect the full picture of business environment, the PCIs are based on covering main business-critical issues. There have been, however, changes in issues in years to update changes in the economic environment of Vietnam. Since 2009, the sub-indices of the PCI has been stable and included nine unify indices. According to the PCI's standards, a province that is considered to perform well on all nine PCI sub-indices is the one that has: (1) low entry costs for business start-up; (2) easy access to land and security of business premises; (3) a transparent business environment and equitable business information; (4) minimal informal charges; (5) has limited time requirements for bureaucratic procedures and inspections; (6) proactive and creative provincial leadership in solving problems for enterprises; (7) developed and high-quality business support services; (8) sound labor training policies; and (9) fair and effective legal procedures for dispute resolution (USAID/VNCI-VCCI, 2012). The nine sub-indices have replicated every year since 2009 .

To reduce impacts of differences in structural factors (population density, surface area, distance from Ha Noi and Ho Chi Minh city), infrastructure and regions, the PCI uses weights for each sub-indices. The final PCI scores are the weighted sum of nine sub-indices and ranks provinces for each year.

In spite of ranking system developed, "The PCI exercise is not intended to be a purely academic exercise, nor to 'point fingers' at individual provinces that rank lowest or highest. Rather, the PCI attempts to provide robust information that can help provinces and municipalities to identify where-and how-they can pursue economic governance reforms to optimal effect" (USAID/VNCI-VCCI, 2007). However, in fact, the rank of PCI is also the basis for the central government to compare provincial performance in different parts of the country and helps to identify areas where the central government may wish to strengthen supervisory functions and improve decentralization, infrastructure and regional integration. On the other hand, investors and businesses may use 
PCI data to consider investment and expansion in specific provinces.

As mentioned above, the current PCI scores are conducted based on nine sub-indices. To explore the relation between these indices and business growth, (USAID/VNCI-VCCI, 2009) regressed outcome variables (private enterprises per 1,000 citizens, investment per capita, and profit per enterprise) by each sub-indices with controlling for other business environment factors. The report concludes that "a one-unit improvement in transparency is associated with a $13 \%$ improvement in the number of enterprises per 10,000 citizens, a $17 \%$ improvement in investment per capita, and a 62 million VND increase in profit per enterprise", for instance. It means that changes of sub-indices may impact to changes in numbers of enterprises and other business indicators. However the final PCI scores or ranks are conducted by the sum of the sub-indices without including changes in outcomes.

This study includes two objectives:

(1) Supply an additional approach to assess the impact of the PCI in investment attraction and lead to another rank which supplements to the current rank of PCI. The new ranking uses the same nine sub-indices of PCI. However, instead of conducting these indices into the final PCI score, they are used as inputs to "produce" outputs which are business growth and other business indicators by employing data envelopment analysis (DEA) method. The new rank is based on technical efficiency scores of DEA for each province. The result of the study should answer the question how changes in the sub-indices of PCI are directly reflected by changes in business in each province.

(2) Assess changes in productivity and its decompositions for 63 provinces during the period 2009-2011 by using the DEA-based Malmquist productivity index.

\section{Methods and Materials}

\subsection{Measuring Efficiency}

The concept of efficiency was proposed by Farrell (1957) based on the work of Debreu (1951) and Koopmans (1951). In his study, Farrell distinguished two components of efficiency: technical efficiency and allocative efficiency. Technical efficiency reflects the ability of a firm to obtain maximum output based on a given set of inputs. Meanwhile, allocative efficiency measures the ability to use the optimal input set, with available prices and production techniques respectively. The allocative efficiency is therefore called as price efficiency. Technical efficiency and allocative efficiency can be combined to measure economic efficiency (or overall efficiency) of a firm.

Technical efficiency can be measured under input-orientation or output-orientation. While the input-orientation answers the question: "By how much can input quantities be proportionally reduced without changing the output quantities produced?", the output-orientation on the opposed direction addresses "By how much can output quantities be proportionally expanded without altering the input quantities used?" (Coelli et al., 1998).

To illustrate the case of output-orientation, Farrell used an example of a firm that includes two outputs $\left(\mathrm{y}_{1}, \mathrm{y}_{2}\right)$ and one input (x) under the assumption of constant returns to scale (CRS). Then, we can represent the technology by a unit production possibility curve $\mathrm{ZZ}$ ' in Figure 2 . The point A lies below the production possibility and therefore it corresponds to an inefficient firm. The distance of $A B$ represents technical inefficiency or the amount of output could be increased without using more than the observed amount of any input. In this case, the output-oriented technical efficiency (TE) is measured by the ratio: TE $=0 \mathrm{~A} / 0 \mathrm{~B}$.

In the case of available revenue information, the iso-revenue line DD' can be added to measure allocative efficiency (AE). Then, allocative efficiency is the ratio: $\mathrm{AE}=0 \mathrm{~B} / 0 \mathrm{C}$. Combining technical efficiency and allocative efficiency generates the concept of the overall economic efficiency:

$$
E E=T E x A E=(O A / O B) \times(O B / O C)=O A / O C
$$




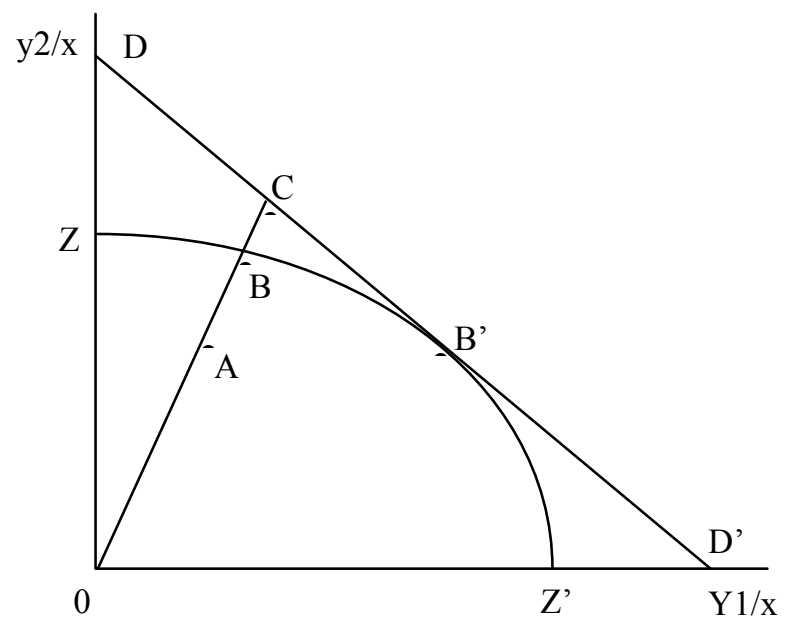

Figure 1. Technical and allocative efficiencies under output orientation

(Source: Coelli et al., 1998)

The analysis above illustrates Farrell's output-oriented measure on the ability of a firm to increase outputs without changing inputs. The alternative approach known as input-orientation measures the ability of a firm to reduce inputs without changing outputs. In practice, the choice between input-oriented and output-oriented measures depends on the objective of input minimization (input-oriented measure) or output maximization (output-oriented measure) without changing the remaining elements (FAO, 2003).

\subsection{Data Envelopment Analysis (DEA)}

Technical efficiency can be measured by using parametric or non-parametric approaches. In this study, a non-parametric data envelopment analysis (DEA) model is employed to analyze the technical efficiency. DEA was explained in Färe (1985) as a non-parametric piece-wise surface (or frontier) over the data (Coelli et al., 1998). Furthermore, output-oriented DEA is preferred in this study because the study's target is to measure business growth in relation to the given PCI's sub-indices. According to Färe et al. (1993) and Pascoe et al. (2003) the output-oriented DEA model can be described as follows:

$$
\begin{aligned}
& \operatorname{Max} \emptyset_{l} \\
\text { s.t } \sum z_{j} x_{j, n}= & \lambda_{j, n} x_{j, n} \quad n \in \alpha \\
& \operatorname{Max} \Phi_{l}
\end{aligned}
$$

where is scalar showing by how much the production of each firm can increase output, $u_{j, m}$ is the amount of output $\mathrm{m}$ by firm $j, x_{j, n}$ is the amount of input $\mathrm{n}$ used by decision making unit DMUj and $z_{j}$ are the weighting factors. Inputs include fixed factors, defined by the set, and variable factors defined by the set $\hat{\alpha}$. To calculate the measure of capacity output, the bounds on the sub-vector of variable inputs, $x_{\widehat{\alpha}}$, need to be relaxed. This is achieved by allowing these inputs to be unconstrained through introduction a measure of the input utilization rate $\left(\lambda_{j, n}\right)$, itself estimated in the model for each DMUj and variable input $\mathrm{n}$. The restriction $\sum_{j} Z_{j}=1$ allows for variable returns to scale.

\subsection{The Malmquist Index}

The Malmquist index measures the total factor productivity (TFP) growth. TFP index is defined using distance function, where an output distance function is used to consider a maximum proportional expansion of the output, $\mathrm{y}$, given the inputs, $\mathrm{x}$. The TFP change (tfpch) in time $t+1$ and $t$ can be decomposed into (1) technical efficiency change or catching up effect, and (2) technical change or shifts of the frontier or innovation as follows:

$$
\begin{gathered}
m=\left[\frac{d^{t}\left(x^{t+1}, y^{t+1}\right)}{d^{t}\left(x^{t}, y^{t}\right)} x \frac{d^{t+1}\left(x^{t+1}, y^{t+1}\right)}{d^{t+1}\left(x^{t}, y^{t}\right)}\right]^{1 / 2}=\frac{d^{t+1}\left(x^{t+1}, y^{t+1}\right)}{d^{t}\left(x^{t}, y^{t}\right)} x\left[\frac{d^{t}\left(x^{t+1}, y^{t+1}\right)}{d^{t+1}\left(x^{t+1}, y^{t+1}\right)} \times \frac{d^{t}\left(x^{t}, y^{t}\right)}{d^{t+1}\left(x^{t}, y^{t}\right)}\right]^{1 / 2} \\
\text { effch (technical efficiency change) }=\frac{d^{t}\left(x^{t+1}, y^{t+1}\right)}{d^{t}\left(x^{t}, y^{t}\right)}
\end{gathered}
$$




$$
\begin{aligned}
\text { techch (technical change) } & =\left[\frac{d^{t}\left(x^{t+1}, y^{t+1}\right)}{d^{t+1}\left(x^{t+1}, y^{t+1}\right)} x \frac{d^{t}\left(x^{t}, y^{t}\right)}{d^{t+1}\left(x^{t}, y^{t}\right)}\right]^{1 / 2} \\
t f p c h & =e f f c h * \text { techch }
\end{aligned}
$$

A value of $m$ greater than one indicates a growth in productivity. When $m>1$, this reflects productivity improvement; $\mathrm{m}<1$, declines in productivity, and no improvement when $\mathrm{m}=1$.

The technical efficiency change (effch), in turn, can be further decomposed into pure efficiency change (pech) and scale change $(\operatorname{sech})$ : effch $=$ pech $*$ sech. The pech component reflects the real or genuine efficiency change that is associated with the adoption of the technology, while the sech represents changes that are due to the changes in size or scale of DMUs.

\subsection{Bootstrapping}

Efron (1979) introduced the concept of bootstrap as a very general resampling procedure for estimating the distribution of statistics based on independent observations. Follow his work, Simar and Wilson (1998) and many recent studies have proposed the bootstrap strategy for analyzing the sensitivity of the efficiency measures to sampling variation, providing confidence intervals and corrections for the bias inherent in the DEA procedure. Furthermore, the bootstrapping method is also used to estimate confidence intervals in the Malmquist index. Generally bootstrapping follows the following basic steps:

1) Construct an empirical probability distribution from the sample;

2) Resample the data set by a specified number of times;

3) Calculate the specific statistic from each sample;

4) Find the standard deviation of the distribution of that statistic.

\subsection{Data and Analysis}

The PCIs have been annually conducted since 2005. However, only from the PCI 2009 to the current PCI 2012, the same sub-indices are repeated the surveys. To compare between years, this study only uses the weighted sub-indices of the PCI data in 2009, 2010 and 2011 as inputs respectively to available output data. Nine inputs are (1) entry costs, (2) land access, (3) transparency, (4) time costs, (5) informal charges, (6) proactivity, (7) business support services, (8) labor training and (9) legal institutions which are weighted by 10, 5, 20, 15, 10, 10, 5,20 and $5 \%$ respectively (USAID/VNCI-VCCI, 2009).

In the aspect of outputs, to avoid bias in business data between different provinces, all outputs are converted to growth rates instead of numbers. This allows to compare business growth between developed province and low-developed province. These outputs include both foreign direct investment (output 1,2,3) and domestic investment (output 4, 5, 6, 7, 8) which are: (1) FDI business growth (change in number of enterprises), (2) total FDI capital growth, (3) FDI registered charter capital growth, (4) business growth, (5) average employee growth per enterprise, (6) average capital growth per enterprise, (7) average fixed asset and long-term investment growth per enterprise, (8) average net turnover growth per enterprise. More detailed statistics of inputs and outputs should be found in Table 1, Appendices.

For the first objective, to compare with available PCIs, TE scores under variable returns to scale DEA are bootstrapped by 2,000 replications and 5\% of the confidence intervals. The bootstrap allows to rank TEs while the DEA without bootstrap may result some efficient DMUs which have TE $=1$ and therefore be impossible to compare between efficient DMUs. All calculations of TE are done by the FEAR 2.0 package which was developed by Wilson (2008). In the second objective, all Malmquist index averages are geometric means which are estimated under DEAP 2.1 by Coelli (1996).

\section{Empirical Results}

\subsection{Technical Efficiency Scores and PCIs}

Using the data set including eight outputs and nine inputs, values of TE are estimated at three years: 2009, 2010 and 2011 for 63 provinces in Vietnam. Basically, the mean values of TE do not much change between these years, $1.11,1.10$ and 1.12 respectively. However, there are differences in ranking between TE-based ranking and PCI-based ranking. The reason is that PCIs are weighted sum of sub-indices while these weighted sub-indices are inputs to estimate technical efficiency scores. The new ranking method is interested in how inputs affecting to growth of outputs which are business outcomes.

In PCI 2009, Da Nang province is the highest rank because the weighted sum of sub-indices of this province is relatively higher than similar indicators of other provinces. However in TE 2009, growth in nine outputs of Da 
Nang are not respectively high as its input growth. This leads the loosing position of this province to $19^{\text {th }}$ in the rank. On the other hand, Thai Nguyen province from the $31^{\text {th }}$ rank in PCI changes to the first position in the TE rank. It does not mean the outputs of Thai Nguyen province are higher than outputs of other provinces. As mentioned above, the output-oriented DEA measures on the ability of a province to increase its outputs without changing inputs. On the other words, the set of inputs and outputs of Thai Nguyen province is relatively optimal than other provinces.

Hanoi and Ho Chi Minh city are other examples. Enterprises in these two cities may have positive assessments on administrative performance improvement of the local governments, respectively the $33^{\text {th }}$ and $16^{\text {th }}$ rank in PCI 2009. However these assessments does not lead to respective increasing in investment. To improve their rank, it requires a higher growth of outputs compared to their real situations. The similar cases can be found in the year 2010 and 2011. The detail statistic results should be found in Table 1.

Table 1. Descriptive statistics to the inputs, outputs and main results in output-oriented DEA

\begin{tabular}{|c|c|c|c|c|c|c|c|c|c|c|c|c|c|}
\hline \multirow{2}{*}{\multicolumn{2}{|c|}{ Inputs (score) }} & \multicolumn{4}{|c|}{2009} & \multicolumn{4}{|c|}{2010} & \multicolumn{4}{|c|}{2011} \\
\hline & & Mean & Std. & Min & Max & Mean & Std. & Min & Max & Mean & Std. & Min & Max \\
\hline \multicolumn{2}{|c|}{ 1. Entry Costs } & 0.83 & 0.06 & 0.65 & 0.95 & 0.66 & 0.07 & 0.51 & 0.81 & 0.85 & 0.05 & 0.73 & 0.94 \\
\hline \multicolumn{2}{|c|}{ 2. Land Access } & 0.32 & 0.05 & 0.21 & 0.44 & 0.30 & 0.06 & 0.15 & 0.43 & 0.32 & 0.05 & 0.22 & 0.42 \\
\hline \multicolumn{2}{|c|}{ 3. Transparency } & 1.18 & 0.20 & 0.58 & 1.77 & 1.15 & 0.16 & 0.55 & 1.48 & 1.17 & 0.12 & 0.90 & 1.47 \\
\hline \multicolumn{2}{|c|}{ 4. Time Costs } & 0.98 & 0.16 & 0.55 & 1.34 & 0.95 & 0.14 & 0.67 & 1.26 & 0.99 & 0.14 & 0.57 & 1.24 \\
\hline \multicolumn{2}{|c|}{ 5. Informal charges } & 0.61 & 0.09 & 0.46 & 0.81 & 0.64 & 0.08 & 0.46 & 0.85 & 0.68 & 0.10 & 0.45 & 0.86 \\
\hline \multicolumn{2}{|c|}{ 6. Proactivity } & 0.50 & 0.17 & 0.19 & 0.94 & 0.52 & 0.13 & 0.27 & 0.81 & 0.47 & 0.16 & 0.14 & 0.94 \\
\hline \multicolumn{2}{|c|}{ 7. Business support services } & 0.26 & 0.05 & 0.14 & 0.43 & 0.28 & 0.05 & 0.17 & 0.44 & 0.18 & 0.05 & 0.09 & 0.36 \\
\hline \multicolumn{2}{|c|}{ 8. Labor training } & 0.96 & 0.16 & 0.56 & 1.54 & 1.06 & 0.12 & 0.59 & 1.49 & 0.96 & 0.09 & 0.77 & 1.16 \\
\hline \multicolumn{2}{|c|}{ 9. Legal Institutions } & 0.27 & 0.04 & 0.18 & 0.37 & 0.25 & 0.05 & 0.13 & 0.36 & 0.28 & 0.04 & 0.16 & 0.35 \\
\hline \multirow{2}{*}{\multicolumn{2}{|c|}{$\begin{array}{c}\text { Outputs ( } \% \text { change between the current } \\
\text { year and the previous year) }\end{array}$}} & \multicolumn{4}{|c|}{$2009 / 2008$} & \multicolumn{4}{|c|}{$2010 / 2009$} & \multicolumn{4}{|c|}{$2011 / 2010$} \\
\hline & & Mean & Std. & Min & Max & Mean & Std. & Min & Max & Mean & Std. & Min & Max \\
\hline \multirow{3}{*}{ 高 } & 1. Business growth & 108.46 & 14.22 & 75.88 & 165.00 & 118.40 & 25.59 & 92.31 & 240.00 & 115.09 & 20.17 & 66.67 & 204.24 \\
\hline & 2. Total FDI capital growth & 125.36 & 106.77 & 53.97 & 934.32 & 313.83 & 1392.54 & 49.44 & 11148.57 & 116.35 & 29.16 & 6.75 & 197.93 \\
\hline & 3. FDI registered charter capital growth & 109.85 & 23.95 & 63.96 & 182.99 & 135.31 & 82.63 & 55.20 & 650.46 & 119.62 & 50.46 & 25.28 & 452.34 \\
\hline \multirow{5}{*}{ 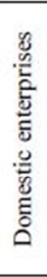 } & 4. Business growth & 117.92 & 16.26 & 66.86 & 200.00 & 113.56 & 8.93 & 93.80 & 140.80 & 119.71 & 12.18 & 87.68 & 163.61 \\
\hline & $\begin{array}{l}\text { 5. Average employee growth per } \\
\text { enterprise } \\
6 . \text { Average capital growth per }\end{array}$ & 115.15 & 12.16 & 66.86 & 155.10 & 114.16 & 10.43 & 99.76 & 155.75 & 116.44 & 13.17 & 82.38 & 150.51 \\
\hline & enterprise & 128.92 & 28.89 & 66.86 & 296.02 & 123.08 & 20.43 & 75.98 & 197.23 & 128.33 & 29.86 & 87.68 & 291.38 \\
\hline & $\begin{array}{l}\text { 7. Average fixed asset and long-term } \\
\text { investment growth per enterprise }\end{array}$ & 131.27 & 41.21 & 66.86 & 390.62 & 120.84 & 20.78 & 66.57 & 204.10 & 130.86 & 48.56 & 87.68 & 476.82 \\
\hline & $\begin{array}{l}\text { 8. Average net tumover growth per } \\
\text { enterprise }\end{array}$ & 120.59 & 20.78 & 66.86 & 215.71 & 122.45 & 19.15 & 47.39 & 174.05 & 128.41 & 23.94 & 87.68 & 253.01 \\
\hline \multirow{2}{*}{\multicolumn{2}{|c|}{ Results }} & \multicolumn{4}{|c|}{2009} & \multicolumn{4}{|c|}{2010} & \multicolumn{4}{|c|}{2011} \\
\hline & & Mean & Std. & Min & $\operatorname{Max}$ & Mean & Std. & Min & Max & Mean & Std. & Min & Max \\
\hline $\mathrm{Tec}$ & cal efficiency (DEA) & 1.11 & 0.09 & 1.04 & 1.48 & 1.10 & 0.07 & 1.03 & 1.33 & 1.12 & 0.09 & 1.04 & 1.50 \\
\hline \multicolumn{2}{|c|}{ PCI } & 59.12 & 6.21 & 45.43 & 75.96 & 58.10 & 4.87 & 48.91 & 69.77 & 59.44 & 4.66 & 50.98 & 73.53 \\
\hline & & \multicolumn{4}{|c|}{$2009-2011$} & & & & & & & & \\
\hline & Mean & Std. & Min & Max & & & & & & & & \\
\hline $\mathrm{Tec}$ & cal efficiency change (effch) & 1.00 & 0.07 & 0.83 & 1.22 & & & & & & & & \\
\hline Tec & cal change (techch) & 1.05 & 0.10 & 0.70 & 1.26 & & & & & & & & \\
\hline Pure & fficiency change (pech) & 1.00 & 0.06 & 0.83 & 1.20 & & & & & & & & \\
\hline Sca. & hange (pech) & 1.00 & 0.02 & 0.97 & 1.04 & & & & & & & & \\
\hline Tot: & actor productivity change (tfpch) & 1.05 & 0.14 & 0.66 & 1.50 & & & & & & & & \\
\hline
\end{tabular}

Source: FIA (2009, 2010, 2011, 2012); USAID/VNCI-VCCI $(2009,2010,2011)$ and author's calculation. 


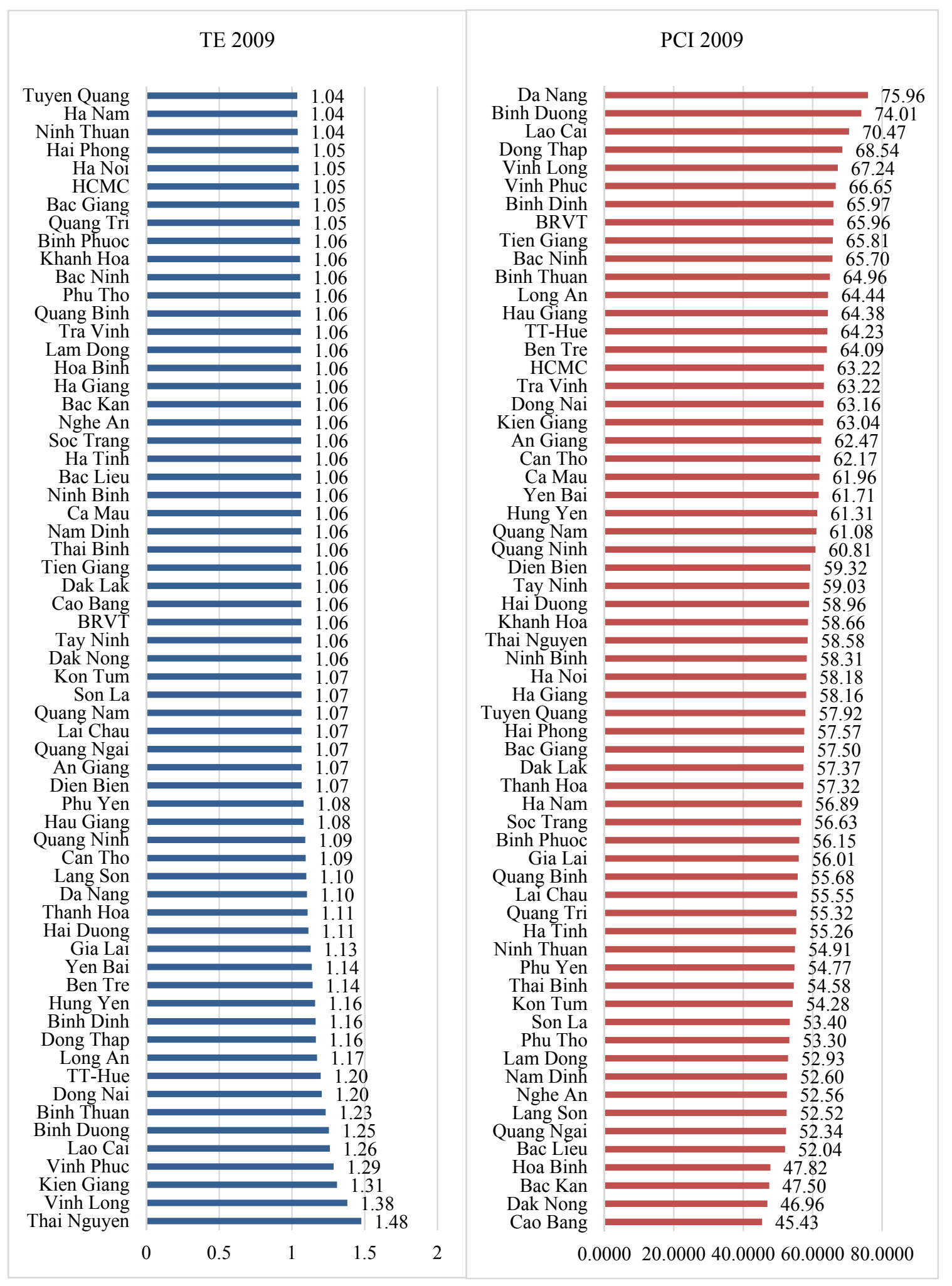

Figure 2. Ranking comparison between TE (DEA) 2009 and PCI 2009

(Source: Author's calculation and USAID/VNCI-VCCI, 2009) 


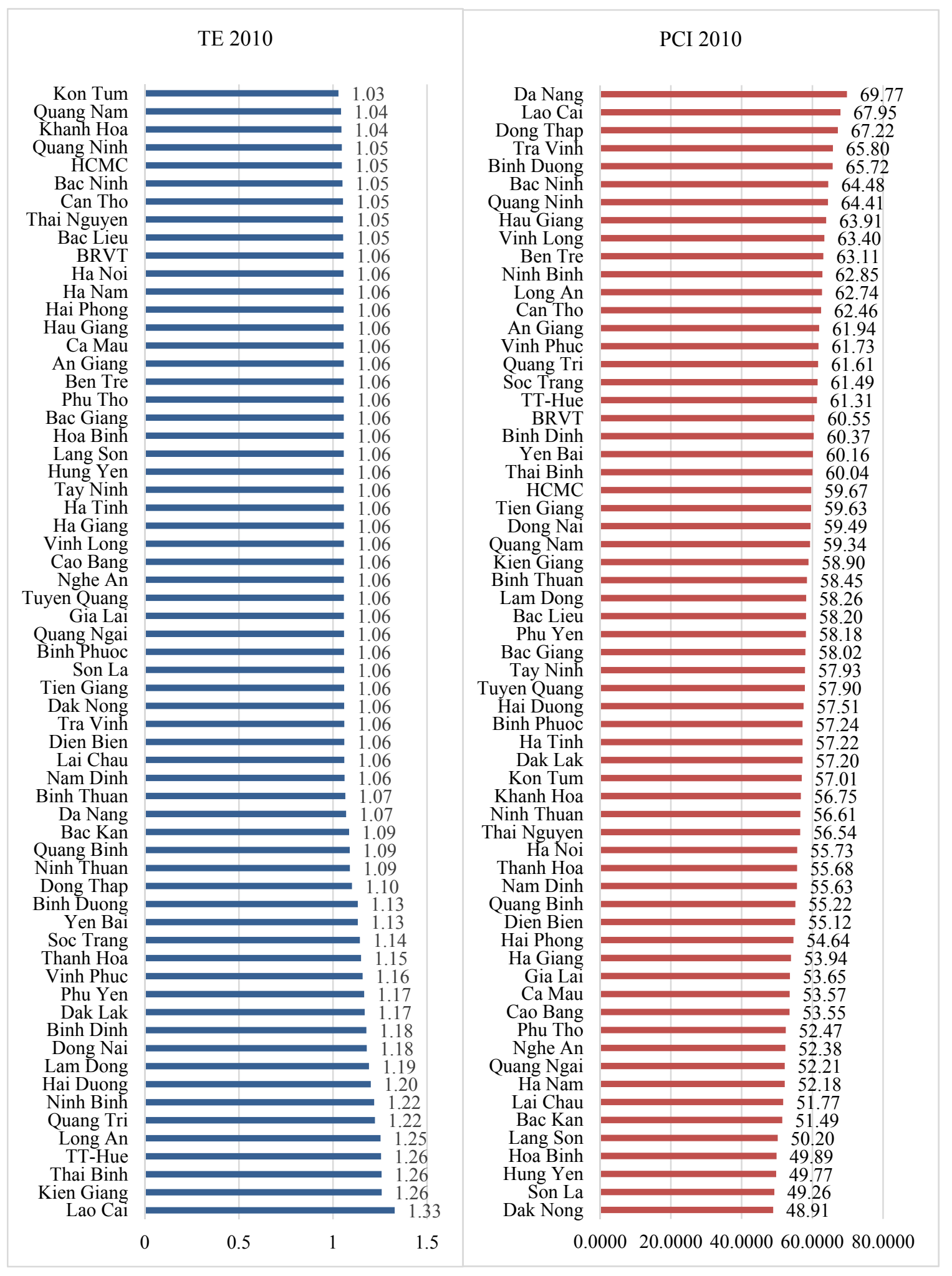

Figure 3. Ranking comparison between TE (DEA) 2010 and PCI 2010

(Source: Author's calculation and USAID/VNCI-VCCI, 2010) 


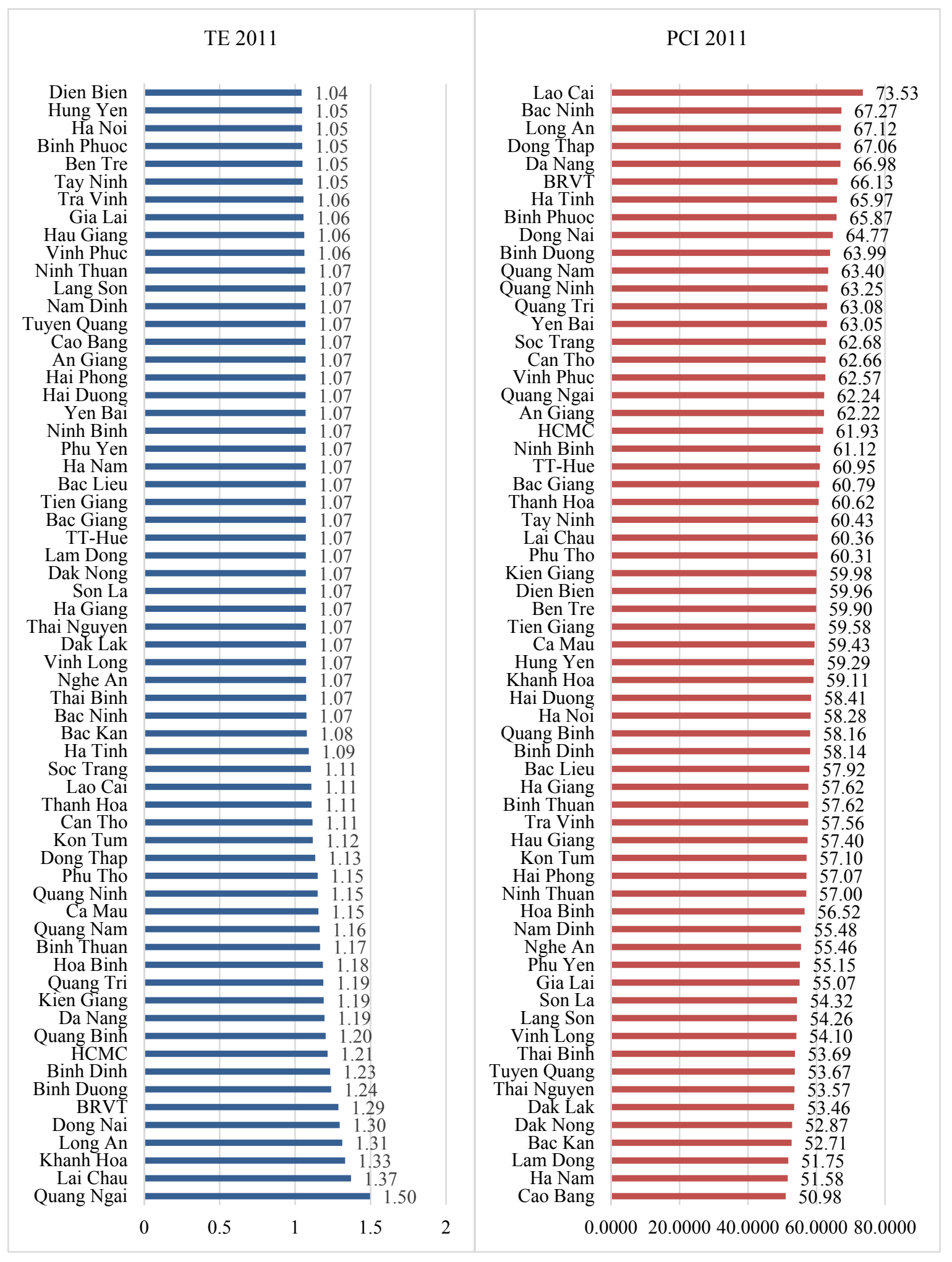

Figure 4. Ranking comparison between TE (DEA) 2011 and PCI 2011

(Source: Author's calculation and USAID/VNCI-VCCI, 2011) 
To identify differences and equivalences between PCI ranks and TE ranks, Table 2 describes the correlation matrix of these two indexes. The correlative level of TE and PCI in 2009 is 0.4722 at $5 \%$ significant level. In other years, these numbers are 0.3553 and 0.3569 in 2010 and 2011 respectively. These numbers reflect a not high correlation between PCI and TE ranks. The reason of these differences should be explained by additional business outcomes as outputs in DEA models.

Table 2. Correlation matrix of TEs (DEA) and PCIs

\begin{tabular}{lllllll}
\hline & TE 2009 & TE 2010 & TE 2011 & PCI 2009 & PCI 2010 & PCI 2011 \\
\hline TE 2009 & 1.000 & & & & \\
TE 2010 & 0.318 & 1.000 & & & \\
TE 2011 & 0.045 & 0.076 & 1.000 & & \\
PCI 2009 & $\mathbf{0 . 4 7 2}$ & 0.210 & 0.149 & 1.000 & 1.000 & 0.597 \\
PCI 2010 & 0.299 & $\mathbf{0 . 3 5 5}$ & 0.027 & 0.776 & 0.616 & 0.00 \\
PCI 2011 & 0.120 & 0.240 & $\mathbf{0 . 3 5 7}$ & & \\
\hline
\end{tabular}

Source: Author's calculation.

\subsection{The Decomposition of the Malmquist Index}

The TE rank analyses efficiency scores in each year, while the Malmquist index describes changes in productivity, technical efficiency and technology during two periods, 2009 and 2011. The Figure 5 ranks provinces by total factor productivity change. According to its results, Thai Nguyen province has highest productivity improvement (1.5) while $\mathrm{Ca}$ Mau is the less improvement province. Looking insights of the decomposition of total factor productivity, we can identify important contributions of both technical efficiency growth (1.217) and technical growth (1.232). In the opposite position, total factor productivity change of Ca Mau province is 0.675 less than 1 . It reflects that productivity has been declining during the period of 2009-2011. In two compositions of Ca Mau's total factor productivity change, technical change (0.696) is less than technical efficiency change (0.944). Technical change in this case reflects the downward shift of the frontier or how the local government combines their input set to attract investment, for instance. 
\begin{tabular}{l|l|l|l|}
$\mathrm{Ca} \mathrm{Mau}$ & 0.657
\end{tabular}

Nghe An

BRVT

Quang Ngai

Hoa Binh

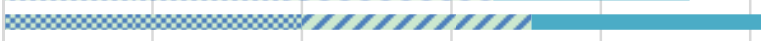

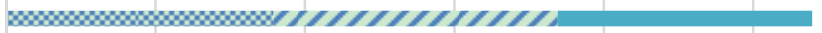

Dak Lak

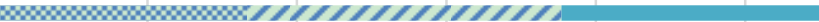

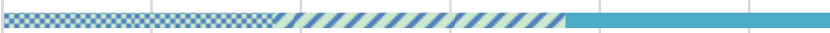

$\mathrm{HCMC}$

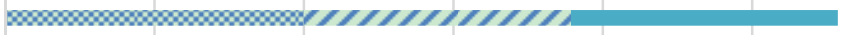

Lai Chau

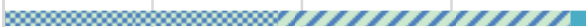

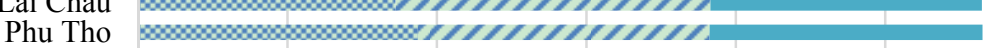

Khanh Hoa

Son La

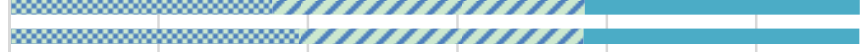

Quang Ninh

Quang Binh

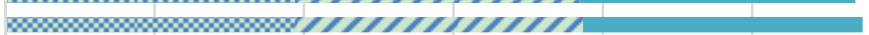

Kon Tum

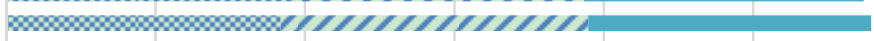

Can Tho

Long An

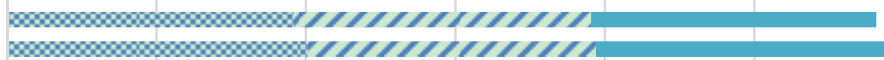

Dong Nai

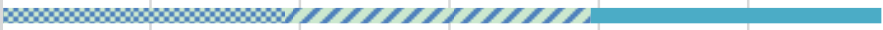

Bac Kan

Tay Ninh

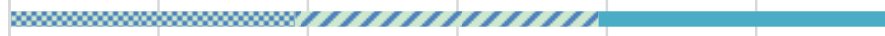

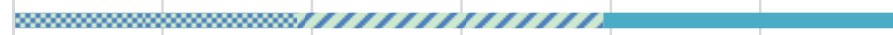

Quang Tri

Ninh Thuan

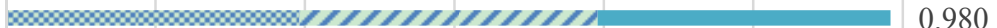

Soc Trang

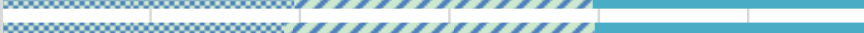

Thanh Hoa

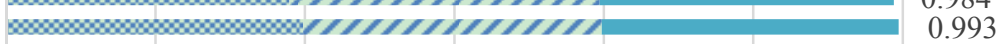

Ha Noi

Ha Tinh

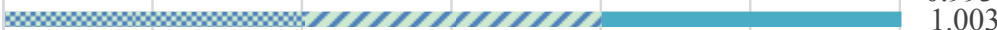

Hai Phong

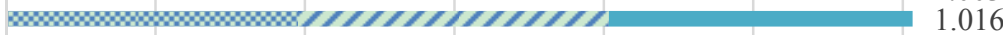

Dong Thap

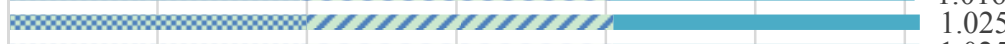

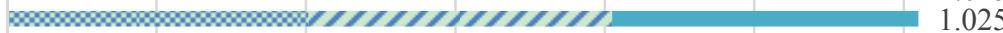

uyen Quang

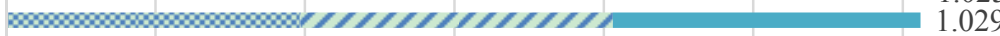

\$

Cao Bang sososos

Ha Giang 1.046
1.052

Ninh Binh

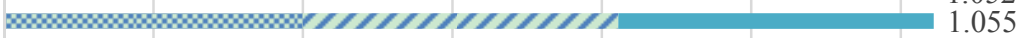

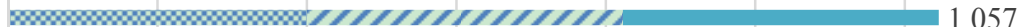

Binh Dinh

Kien Giang

Binh Duong

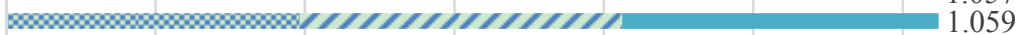

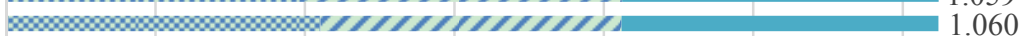

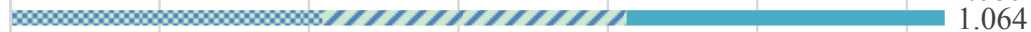

Hau Giang \begin{tabular}{|l|l|l|l|} 
& 1.068
\end{tabular}

Ha Nam

Bac Ninh

Hai Duong

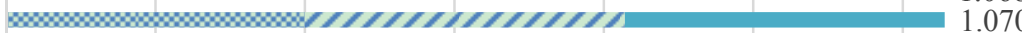

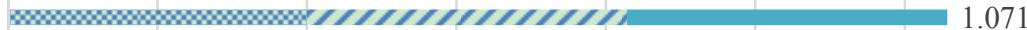

Lao Cai

Binh Thuan

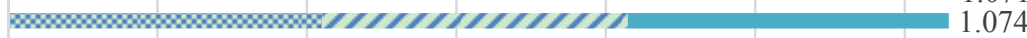

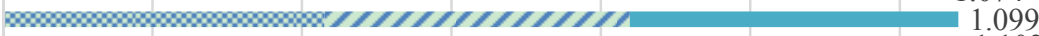

Nam Dinh

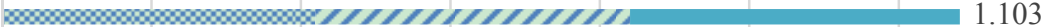

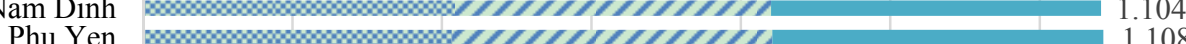

An Giang Gia Lai

Lang Son

Thai Binh

Hung Yen

Vinh Phuc

TT-Hue

Quang Nam

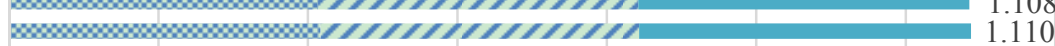

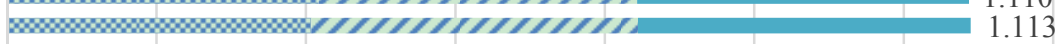

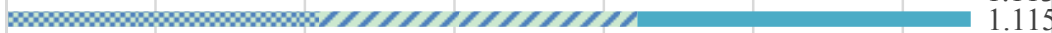

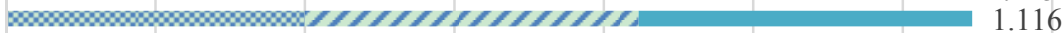

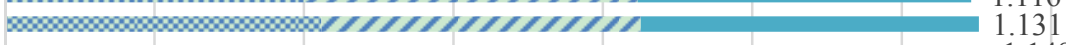

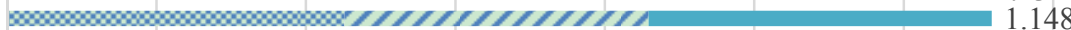

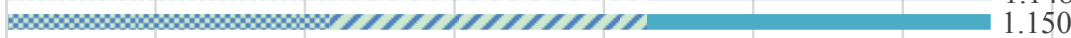

Dien Bien $000000000000000000000000000 \%$ 1.157

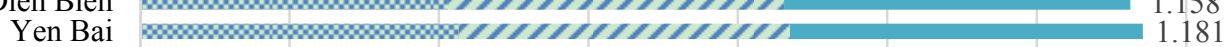

Tien Giang

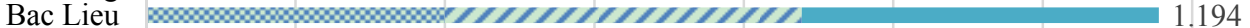

Tra Vinh

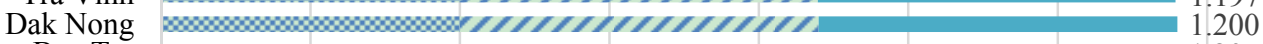

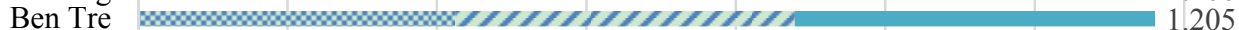

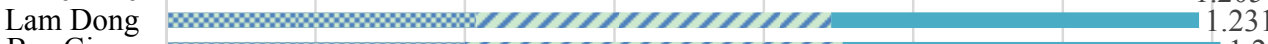

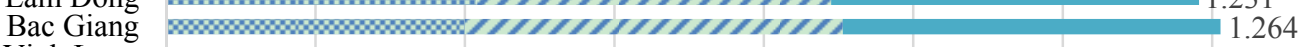

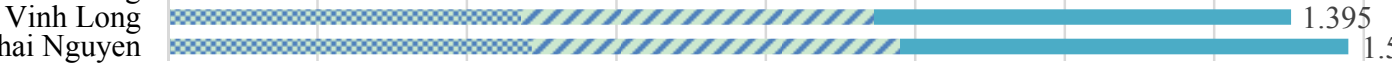

Thai Nguyen
0
0.5
1
1.5
2
2.5
3
3.5
4

Figure 5: Ranking by total factor productivity change in the period 2009-2011

(Source: Author's calculation) 


\section{Conclusion and Discussion}

$\mathrm{PCI}$ is the effective ranking system to reflect the performance and improvement of the local government. Since 2005, many provinces use PCI as the main indicator of their governance reforms. However PCI does not directly reflect relation between its components and growth of business. This study does not aim to replace the current PCI system. It promotes an additional index to the PCI through technical efficiency analysis. Technical efficiency may be an additional approach to supply more understanding on effects of PCI's components to investment. Although there are the significant difference between PCI rank and TE rank, TE rank should be the supplement of PCI rank to lead to a more comprehensive assessment. However, it is necessary to notice that a province with high TE does not mean high investment in that area. TE is simply the comparison between the proportion of inputs and outputs. In the other words, a low TE province may or may not have low investment and therefore improvements are always necessary for investment attraction. Malmquist index, in the other hand, is the important indicator to analysis efforts of the local governments during the period of years. This index may be useful to assess long-term improvement instead of annual assessments of PCI or TE ranks.

However, in methodology aspect, there are some criticism concerning composite indicators that are used for ranking or bench-marking countries' performances. M. Saisana et al. (2004) promotes the use of uncertainty analysis and sensitivity analysis to build composite indicators for countries' rankings. According to the authors, this alternative methodology could provide information on whether the countries' rankings measure anything meaningful and could reduce the possibility that composite indicators may send misleading or non-robust policy messages.

This study is absolutely based on both sub-indices and their weights of the PCI ranking system. This choice allows the new ranking is able to compare and supplement to the current PCI ranking. However it may be also the reason for replication of PCI's weaknesses if existed. It therefore raises demand for future works to rank local government's performance by other alternative methodologies as M. Saisana et al. (2004)'s suggestion, for instance.

\section{References}

Coelli, T. (1996). A Guide to DEAP Version 2.1: A Data Envelopment Analysis (Computer) Program. CEPA Working Papers, No. 8/96.

Coelli, T. J., Rao, D. S. P., O’Donnell, C. J., \& Battese, G. E. (1998). An introduction to efficiency and productivity analysis. Boston: Kluwer Academic Publishers. http://dx.doi.org/10.1007/978-1-4615-5493-6

Debreu, G. (1951). The coefficient of resource utilization. Econometrica, Journal of the Econometric Society, 19(3), 273-292. http://dx.doi.org/10.2307/1906814

Efron, B. (1979). Bootstrap methods: Another look at the Jackknife. Ann. Statist., 7, 1-26.

FAO, Food and Agriculture Organization of the United Nations. (2003). Measuring and assessing capacity infisheries. 2. Issues and methods. FAO Fisheries Technical Paper. No. 433/2. Rome, FAO.

Färe, R. (1985). The measurement of efficiency of production. Boston, Hingham, MA, U.S.A.: Kluwer-Nijhoff Pub. http://dx.doi.org/10.1007/978-94-015-7721-2

Färe, R., Grosskopf, S., \& Lovell, C. A. K. (1993). Production frontiers. United Kingdom: Cambridge University Press.

Farrell, M. J. (1957). The measurement of productive efficiency. Journal of the Royal Statistical Society, Series A (General), 120(3), 253-290. http://dx.doi.org/10.2307/2343100

FIA, Ministry of Planning and Investment-Foreign Investment Agency. (2009). Foreign Direct Investment in Vietnam by provinces in 2008 .

FIA, Ministry of Planning and Investment-Foreign Investment Agency. (2010). Foreign Direct Investment in Vietnam by provinces in 2009.

FIA, Ministry of Planning and Investment-Foreign Investment Agency. (2011). Foreign Direct Investment in Vietnam by provinces in 2010 .

FIA, Ministry of Planning and Investment-Foreign Investment Agency. (2012). Foreign Direct Investment in Vietnam by provinces in 2011.

Koopmans, T. C. (1951). An analysis of production as an efficient combination of activities. In T. C. Koopmans (Ed.), Activity Analysis of Production and Allocation. New York: John Wiley and Sons, Inc. 
Pascoe, S., Kirkley, J. E., Gréboval, D., \& Morrison-Paul, C. J. (2003). Measuring and assessing capacity in fisheries. 2. Issues and methods. FAO Fisheries Technical Paper. No. 433/2. Rome, FAO.

PCI, The Provincial Competitiveness Index. (2013). Retrieved November 3, 2013, from http://www.pcivietnam.org/about_us.php

Saisana, M., Saltelli, A., \& Tarantola, S. (2004). Uncertainty and sensitivity analysis techniques as tools for the quality assessment of composite indicators. Journal of the Royal Statistical Society: Series A (Statistics in Society), 168(2), 307-323. http://dx.doi.org/10.1111/j.1467-985X.2005.00350.x

Simar, L., \& Wilson, P. W. (1998). Sensitivity analysis of efficiency scores: how to bootstrap in nonparametric frontier models. Management Science, 44(11), 49-61. http://dx.doi.org/10.1287/mnsc.44.1.49

USAID/VNCI-VCCI. (2007). The Vietnam Provincial Competitiveness Index 2007: Measuring economic governance for private sector development.

USAID/VNCI-VCCI. (2009). The Vietnam Provincial Competitiveness Index 2009: Measuring economic governance for business development.

USAID/VNCI-VCCI. (2010). The Vietnam Provincial Competitiveness Index 2010: Measuring economic governance for business development.

USAID/VNCI-VCCI. (2011). The Vietnam Provincial Competitiveness Index 2011: Measuring economic governance for business development.

USAID/VNCI-VCCI. (2012). The Vietnam Provincial Competitiveness Index 2012: Measuring economic governance for business development.

Wilson, P. W. (2008). FEAR 1.0: A Software Package for Frontier Efficiency Analysis with R. Socio-Economic Planning Sciences, 42(4), 247. http://dx.doi.org/10.1016/j.seps.2007.02.001

\section{Copyrights}

Copyright for this article is retained by the author(s), with first publication rights granted to the journal.

This is an open-access article distributed under the terms and conditions of the Creative Commons Attribution license (http://creativecommons.org/licenses/by/3.0/). 